\title{
STEM field-to-field transitions for a better workforce
}

\begin{tabular}{|c|c|}
\hline $\begin{array}{l}\text { A new scheme called OPEN-NJ } \\
\text { at Montclair State University } \\
\text { (MSU) means more students will } \\
\text { be able to gain interdisciplinary } \\
\text { research skills by transitioning } \\
\text { from Biology to Chemistry } \\
\text { or Biochemistry subjects } \\
\text { for graduate-level study. } \\
\text { Students in New Jersey with } \\
\text { an interdisciplinary education } \\
\text { are at an advantage when } \\
\text { entering the STEM workforce } \\
\text { because the state is home to } \\
\text { some biochemical industry } \\
\text { giants. Dr Ninan Goodey and } \\
\text { her collaborators Drs Herbert, } \\
\text { Kasner, Krumins, and Siekierka, } \\
\text { and Gennae Hinson, have been } \\
\text { evaluating the scheme's impact } \\
\text { so that other universities can }\end{array}$ & $\begin{array}{l}\text { his year, millions of students } \\
\text { in the United States will make } \\
\text { a life-changing decision: choosing } \\
\text { a subject for their major. } \\
\text { The sheer number of possibilities is } \\
\text { enough to overwhelm, and any decision } \\
\text { has implications that will last well beyond } \\
\text { the end of their degree. By the time a } \\
\text { student graduates, many opportunities } \\
\text { in further education may be closed } \\
\text { off to them simply because of their } \\
\text { major. Even within Science, Technology, } \\
\text { Engineering and Mathematics (STEM), } \\
\text { a student holding a Bachelor's in one } \\
\text { subject will struggle to enrol in a Master's } \\
\text { course in another, even if the subjects } \\
\text { are closely related and the student has } \\
\text { all of the necessary skills to complete } \\
\text { the course. For universities, allowing }\end{array}$ \\
\hline
\end{tabular}

students to transfrics

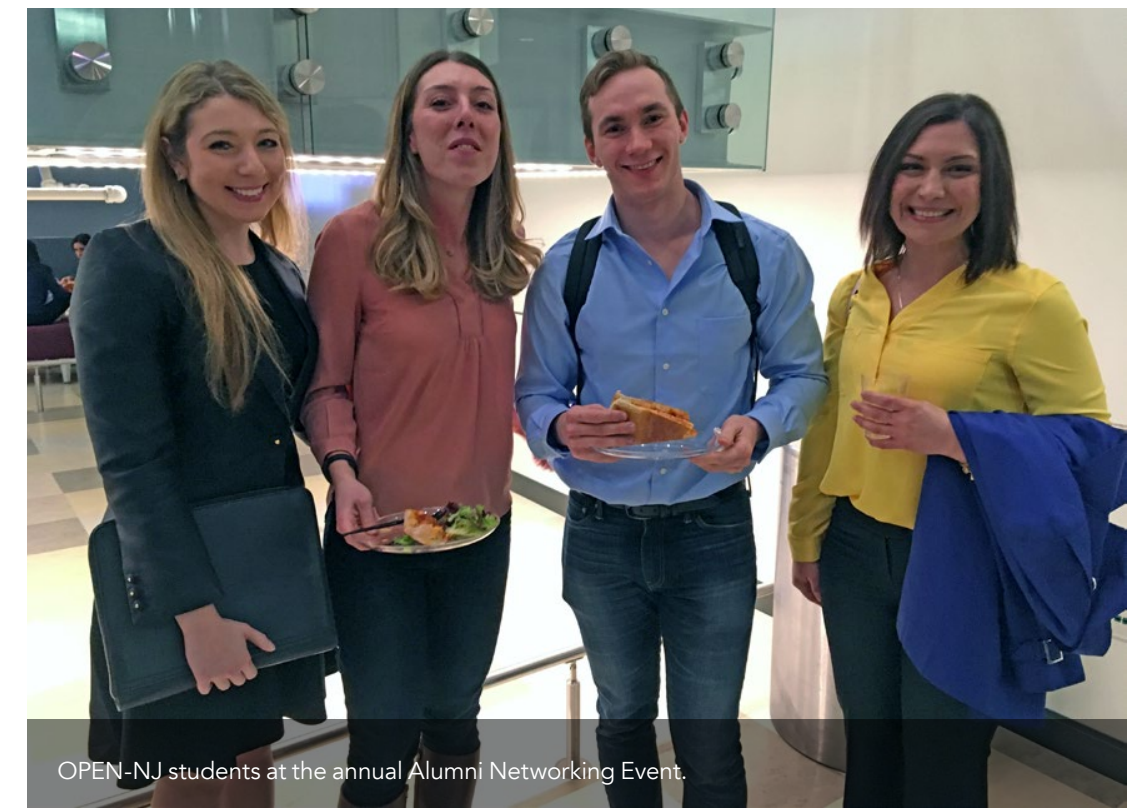

an be too much of a risk: the challenge of learning new material is enough thansition could string a field-to-field high marks, or possibly even drop out before graduating.

\section{A GROWING PROBLEM}

In New Jersey, as is the case in the US nation-wide, there is a shortage of STEM professionals. New Jersey has booming biotechnology and pharmaceutical industries that include the likes of Bayer, Johnson \& Johnson and Merck \& Co., as well as many smaller companies, all of whom need a steady supply of graduates. These industries are a major component of the state's economic output, and the companies provide ob prospects for many New Jersey

When looking for work in these industries, New Jersian STEM graduates benefit from having an interdisciplinary students won't be able to find this kind of opportunity available to them and so continue in the same specialism at graduate level.

\section{OPEN-NJ: A NEW TRACK} Dr Nina Goodey, Professor in the Department of Chemistry and Biochemistry at Montclair State University (MSU), and her collaborators Drs Herbert, Kasner, Krumins, Siekierka, and Ms Gennae Hison, are running a scheme at MSU which creates a new track through university - one that discipline between Bachelor's and
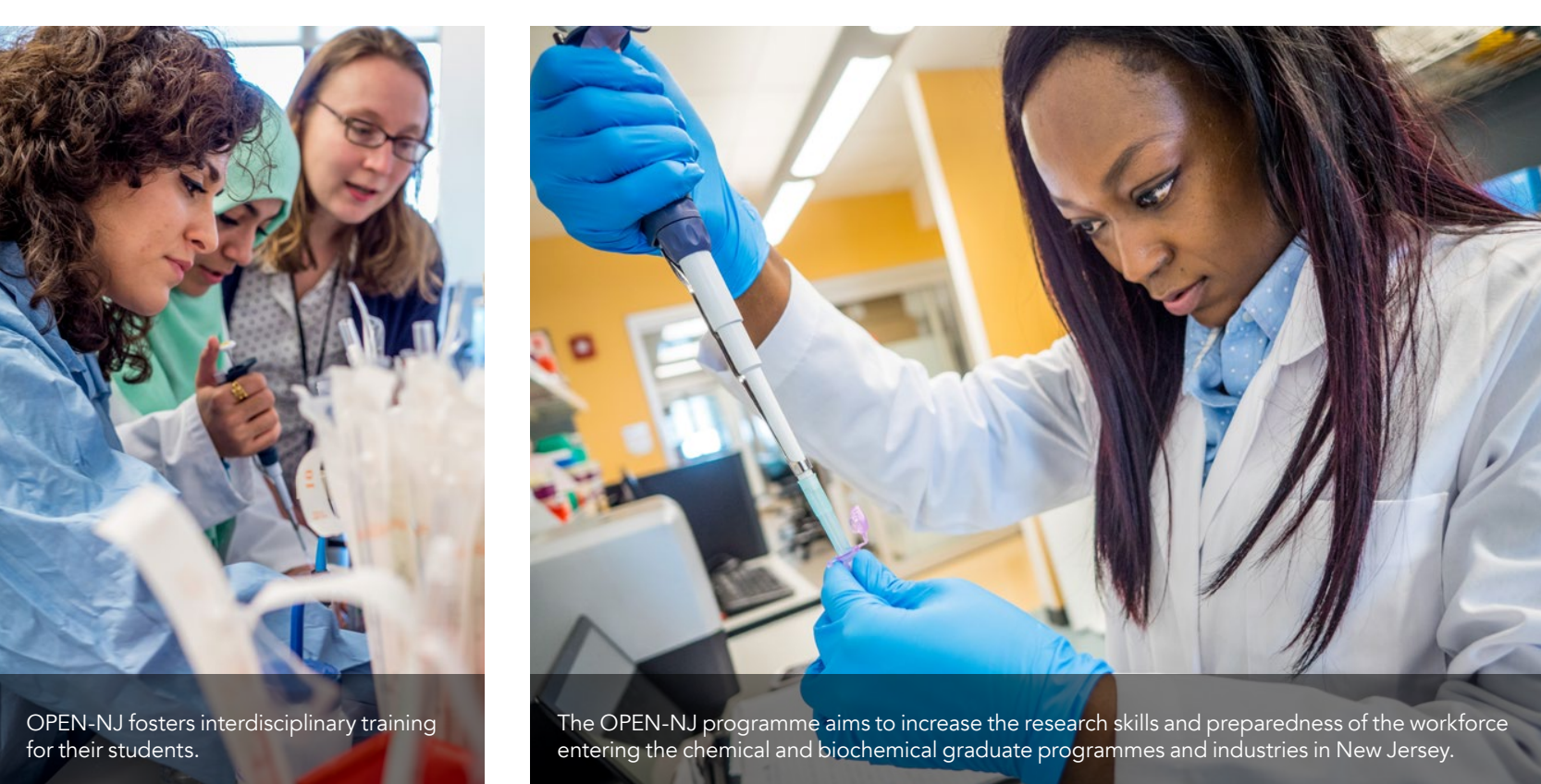

Master's level degrees. To achieve this seemingly simple process $h$ a
a multi-faceted approach.

The programme, called 'Opening Pathways, Engaging, and Networking in Chemistry in Northern New Jersey' (OPEN-NJ) has a primary goal to offer a pathway for students to change fields from Biology and related fields to Chemistry and Biochemistry, with a specific goal of fostering interdisciplinary knowledge in their students, so that the New Jersey STEM workforce is well-educated, skilled and diverse.

The bulk of the programme involves
To counter this disparity, Dr Goodey for Biology majors, the first yt MSU courses in Biochemistry, Analytical Chemistry, Physical Chemistry and Instrumental Analysis. Before the year, students also undergo a self-paced review of General Chemistry II using an online with a tutor.

\section{HOLISTIC APPROACH}

But the scope of the OPEN-NJ project goes beyond just a course-restructure: it aim is to increase the skill and diversity of -known as the transition year-indudes the workforce ente $\mathrm{ng}$ the biochemical

ssion to enhance their career prospects Students have additional exchanges w career mentors to learn about career

options. The focus of the project is heavily directed at preparing students to have excellent career options at the end of their graduate study.

Another major objective of the programme is the provision of mentoring and counselling services to ensure Master's students reach their potentia. Students that can show financial need are accounted for through a scholarship scheme. The approach is therefore a holistic one, taking into account many st the various factors that might hinder creating a Master's

[OPEN-NJ] goes beyond just a coursewho majored in

Biology can achieve

Biology can achieve

at the same level
as those who majore

in chemistry. This is tricky because most Biology graduates will restructure: its aim is to increase the skill and diversity of the workforce entering the biochemical industries level Chemistry courses currently equired for entrance onto the standard Chemistry Master's programm Chemistry majors starting the Chemistry Master's programme at MSU score on average $47 \%$ on the General Chemisty ACS exam, a test used nationally. In comparison, non majors score are at a $37 \%$ of the questions correctly. in north New Jersey.

increasing the career prospects career opportunities, students on the programme are given a rounded provision of professional development career-based workshops covering everything from resume preparation to interview practice to professional networking. Once a year, students on the program meet with professional career panel and networking at this level.

REVIEWING THE PROGRAMME

DrGoodey and her colleagues have performed a review of the programme,
with the intention of discovering trends that can be disseminated in the STEM education community and inform practices in other STEM field-to-field transitions. She hopes that this will mean will ership and support programmes will emulate the best practices from the

The data coming out of the evaluatio stage of the programme is promising: 


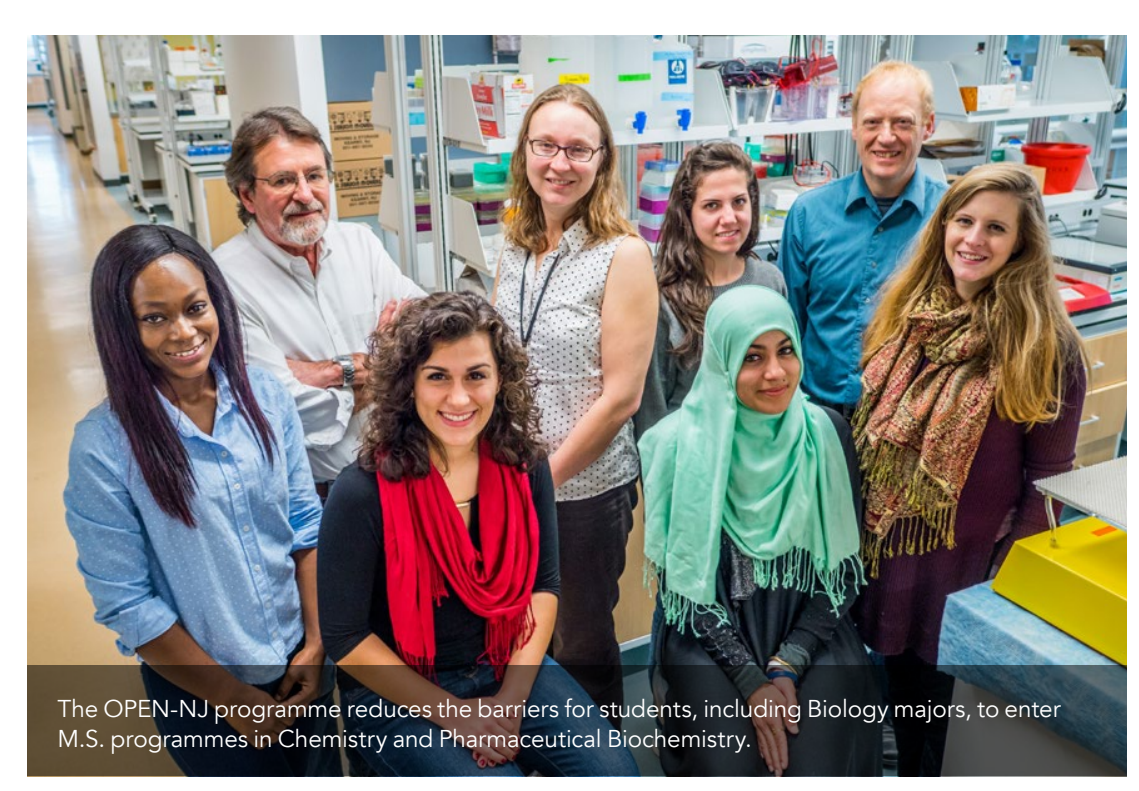

after completing the transition year, in a small sample, Chemistry non-

for students. The downstream effect of the programme is notable. Dr Good

General Chemistry ACS - 20 percentage standards to select for students who have

New workshops are being integrated into the curriculum which include manuscript writing, mock interviews and public speaking.

points higher than students who haven't undertaken the transition year and 10 percentage points higher than even the Chemistry majors. Dr Goodey and her colleagues have found that a review of General Chemistry II was useful - and pinpointed that Physical Chemistry can
be one of the biggest sticking points

a stronger Maths background has had a major influence on retention rates, whic sat at $33 \%$ in the first year. After making the changes, his became $80 \%$ in the second year and is now reaching height of $90 \%$. Students are overwhelmingly positive about the programme - almost

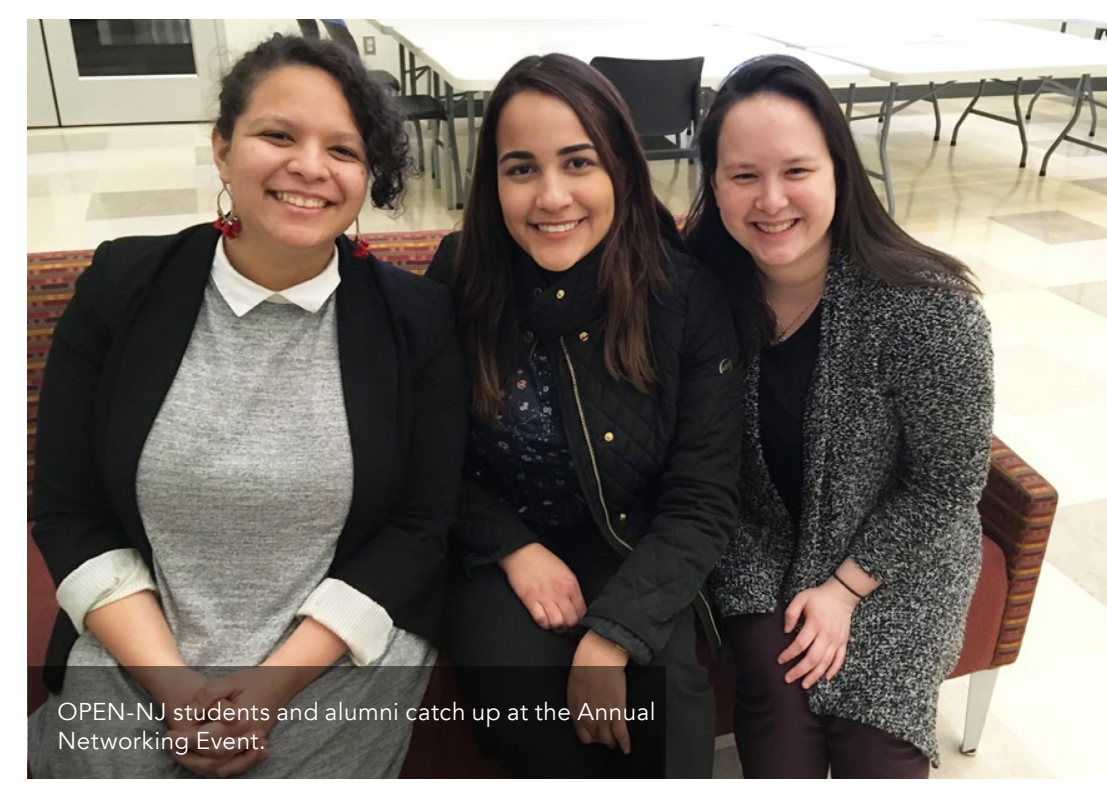

survey said they would recommend Particularly students noted that the programme provided practical and professional help with a high level of interaction, and that the events were informative, helpful, and workshops were insightful.

\section{FUTURE AND INFLUENCE}

But work is not done here - Dr Goodey is still fine-tuning the programme to ensure students have all the support necessary. In the upcoming year, students will get more notice on workshops and won't be required to repeat attend workshops will have mor socir study. Students met other students opportunities to DrGoodey is also planning togramme Drector all OPEN-NJ students. On top of all these, new workshops are being integrated manuscript writing mock inteniews and public speaking.

And so that more students can join onto this programme, $\mathrm{Dr}$ Goodey is visiting local feeder school campuses, which has already resulted in more applications. This year she is planning how the programme can be advertised through career fairs, social media and other streams.

Dr Goodey is now in the process of writing a manuscript to describe the emerging trends from the programm so that other institutions can learn from

In the meantime, the course is having an impact beyond simply providing Northern New Jersey with a well-equipped interdisciplinary workforce; it is also enabling access to education students who wouldn't otherwise necessarily have that option. The programme and the accompanying financial support are already attracting a more diverse cohort, including African-American and Hispanic students. First-generation college students and immigrants are less likely to consider graduate-level study, and Dr Goodey hopes that the programme will be able to boost numbers of these und revresented minorities. And once the review of the program is complete, many more students

Dr Nina Goodey

E: goodeyn@montclairedu T: +1 973-666-1368 T: + 1973-655-3410

Research Objectives

Dr Nina Goodey's research centres on biochemical research and education

\section{Detail}

Department of Chemistry and Biochemistry

Montclair State University

Monar, NJ 07043

Bio

As a Ph.D. student with Dr Stephen Martin, Nina Goodey investigated the substrate selectivity of Phospholipase $C$. As a postdoctoral researcher in the laboratory of Stephen Benkovic, she studied protein engineering and allosteric interactions. She is currently a Professor in the Departmen of Chemistry and Biochemistry at Montclair State University. She teaches Chemistry courses and supervises student laboratory research.

Funding

National Science Foundation Grant Number DUE - 1458499

Collaborators

- Katherine Herbert

- Marc Kasner

- Johnifer Krumins

- Gennae Hinson

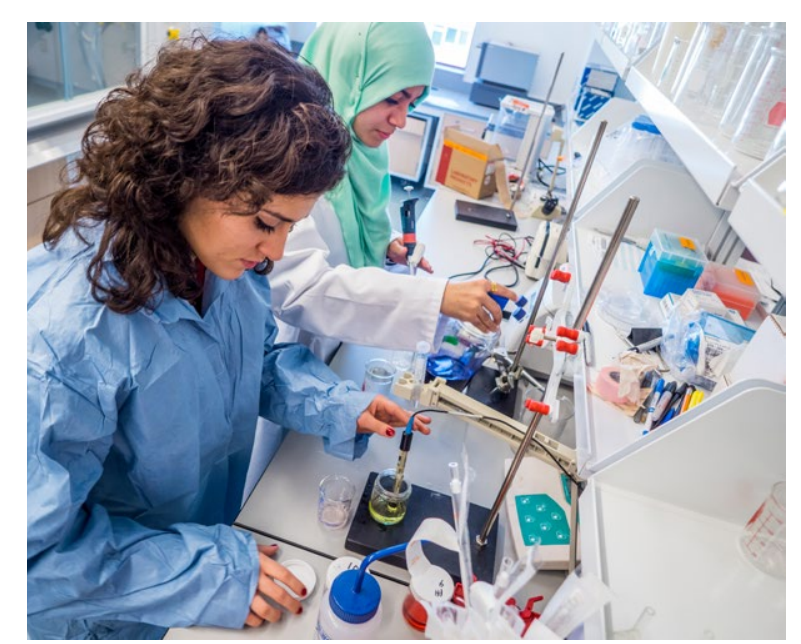

\section{References}

Goodey, N. (2018). Preview of Award 1458499 - Annual Project Report: Opening Pathways, Engaging and Networking in Chemistry in Northern New Jersey (OPEN-NJ). Available at: https://www.montclair.edu/csam/programs-andopporutnities/open-nj/

Goodey, N. (2019). NSF S-STEM Grant: Opening Pathways, Engaging and Networking in Chemistry in Northern New montclair.edu/csam/programs-and-opporutnities/open-ni/

\section{Personal Response}

At this point in your investigation, what

to crese fietd-to-field transition to others hoping

II Many graduate students have family obligations, need commute long distances. The scholarships alleviate some of these challenges but, as the funds only cover tuition, most students in the programme are forced to work to cover living expenses. Larger scholarships, perhaps as a match by the National Science Foundation would allevite these challenges.

Some Biology undergraduates who pursued a MS degree in Chemistry or Biochemistry reported a lack of sense of inclusion in the Chemistry and Biochemistry Department encouraging them tojoin research labs and the Chemisty Club, and including them in departmental outreach events can help students feel more integrated in their new department and discipline.

Students in northern New Jersey, many of whom are necessarily otherwise get exposed to the idea of pursuing a graduate degree. I would recommend strengthening ties between local institutions to make it possible to support students and provide information about graduate and graduate institutions.
ans 